\title{
Mechanisms underlying enhancements in muscle force and power output during maximal cycle ergometer exercise induced by chronic $\beta_{2}$-adrenergic
} stimulation in men

\author{
Morten Hostrup, ${ }^{1,2}$ Anders Kalsen, ${ }^{1,2}$ Johan Onslev, ${ }^{1,2}$ Søren Jessen, ${ }^{1,2}$ Christoffer Haase, ${ }^{2}$ Sajad Habib, \\ (1) Niels Ørtenblad, ${ }^{3,4}$ Vibeke Backer, ${ }^{2}$ and Jens Bangsbo ${ }^{1}$ \\ ${ }^{1}$ Department of Nutrition, Exercise and Sports, Section of Integrated Physiology, University of Copenhagen, Copenhagen, \\ Denmark; ${ }^{2}$ Department of Respiratory Research, Bispebjerg University Hospital, Copenhagen, Denmark; ${ }^{3}$ Department of \\ Sports Science and Biomechanics, University of Southern Denmark, Odense, Denmark; and ${ }^{4}$ Swedish Winter Sports Research \\ Centre, Mid Sweden University, Sundsvall, Sweden
}

Submitted 17 April 2015; accepted in final form 7 July 2015

\begin{abstract}
Hostrup M, Kalsen A, Onslev J, Jessen S, Haase C, Habib S, Ørtenblad N, Backer V, Bangsbo J. Mechanisms underlying enhancements in muscle force and power output during maximal cycle ergometer exercise induced by chronic $\beta_{2}$-adrenergic stimulation in men. J Appl Physiol 119: 475-486, 2015. First published July 9, 2015; doi:10.1152/japplphysiol.00319.2015. - The study was a randomized placebo-controlled trial investigating mechanisms by which chronic $\beta_{2}$-adrenergic stimulation enhances muscle force and power output during maximal cycle ergometer exercise in young men. Eighteen trained men were assigned to an experimental group [oral terbutaline $5 \mathrm{mg} / 30 \mathrm{~kg}$ body weight (bw) twice daily (TER); $n=9$ ] or a control group [placebo (PLA); $n=9$ ] for a 4-wk intervention. No changes were observed with the intervention in PLA. Isometric muscle force of the quadriceps increased $(P \leq 0.01)$ by $97 \pm 29 \mathrm{~N}$ (means $\pm \mathrm{SE}$ ) with the intervention in TER compared with PLA. Peak and mean power output during $30 \mathrm{~s}$ of maximal cycling increased $(P$ $\leq 0.01$ ) by $32 \pm 8$ and $25 \pm 9 \mathrm{~W}$, respectively, with the intervention in TER compared with PLA. Maximal oxygen consumption $\left(\dot{\mathrm{V}}_{2 \max }\right)$ and time to fatigue during incremental cycling did not change with the intervention. Lean body mass increased by $1.95 \pm 0.8 \mathrm{~kg}(P \leq 0.05)$ with the intervention in TER compared with PLA. Change in single fiber cross-sectional area of myosin heavy chain (MHC) I (1,205 \pm \left.$558{\mu \mathrm{m}^{2}}^{2} ; P \leq 0.01\right)$ and MHC II fibers $\left(1,277 \pm 595 \mu \mathrm{m}^{2} ; P \leq 0.05\right)$ of the vastus lateralis muscle was higher for TER than PLA with the intervention, whereas no changes were observed in MHC isoform distribution. Expression of muscle proteins involved in growth, ion handling, lactate production, and clearance increased $(P \leq 0.05)$ with the intervention in TER compared with PLA, with no change in oxidative enzymes. Our observations suggest that muscle hypertrophy is the primary mechanism underlying enhancements in muscle force and peak power during maximal cycling induced by chronic $\beta_{2^{-}}$ adrenergic stimulation in humans.
\end{abstract}

beta-adrenoceptor; $\mathrm{Ca}^{2+}$ handling; contractile properties; muscle growth; doping

$\beta_{2}$-ADRENOCEPTOR AGONISTS ( $\beta_{2}$-agonists) are among the most commonly used drugs worldwide given the high prevalence of asthma, exercise-induced bronchoconstriction, and chronic obstructive pulmonary disease $(24,46,62)$. While their main therapeutic application is to induce bronchodilation, $\beta_{2}$-agonists elicit several extrapulmonary effects $(34,44)$. $\beta_{2}$-Adrenoceptors are abundant throughout the human body and are

Address for reprint requests and other correspondence: J. Bangsbo, Dept. of Nutrition, Exercise and Sports, Univ. of Copenhagen, The August Krogh Bldg., $2^{\text {nd }}$ floor, Universitetsparken 13, DK-2100 Copenhagen, Denmark (e-mail: jbangsbo@nexs.ku.dk). widely expressed in various tissues (44). Chronic administration of oral $\beta_{2}$-agonists has been shown to enhance muscle force and power output during maximal cycling in humans (10, $12,39,40,45,69)$, which based on observations in animals, have been speculated to be attributed to hypertrophy or changes in fiber type composition of skeletal muscle $(21,23$, $51,63,65,81)$. However, limited mechanistic insight exists in humans that can explain enhancements in muscle force and power output during maximal cycling.

While it is well described that chronic $\beta_{2}$-adrenergic stimulation induces muscle hypertrophy in animals $(23,63,67)$, no such effect has been observed in healthy humans $(10,39,40$, 45). This discrepancy may be related to methodology, since human studies relied on measurements of changes in body composition, whereas animal studies determined changes in the cross-sectional area (CSA) and specific weight of skeletal muscle $(9,21,66,81)$. Another explanation could relate to dosing regimen, as the doses used in animal studies were markedly higher than those administered to humans $(44,59)$. The hypertrophic response to $\beta_{2}$-agonists in animals is as such dependent on the dose, route of administration, type of agonist used, and duration of treatment $(14,50,67)$. Most human studies that have investigated effects of chronic $\beta_{2}$-agonists used oral doses of salbutamol $(12,39,40,45)$, whereas limited data exist of other $\beta_{2}$-agonists. In a recent study, acute oral administration of terbutaline was shown to elicit a significant systemic response in trained men (32). Thus it may be that high-dose terbutaline possesses a hypertrophic effect when administered chronically to humans. Moreover, while several animal studies have examined the molecular mechanisms by which chronic $\beta_{2}$-adrenergic stimulation induces hypertrophy of skeletal muscle $(37,52,54,55,75)$, no such studies exist in humans. Attenuation of myostatin has been highlighted as an important factor by which $\beta_{2}$-agonists elicit their hypertrophic effects $(8,33,54,55)$. However, studies suggest that other factors may be involved $(1,37)$. One of these factors could be follistatin, which was recently shown to be associated with hypertrophy in rodents following treatment with the $\beta_{2}$-agonist formoterol (8). The $\beta_{2}$-adrenergic hypertrophic response has also been shown to vary between slow- and fast-twitch muscles of animals $(21,66,81)$. To our knowledge, no studies in humans have investigated the effect of chronic administration of $\beta_{2}$-agonists on the expression of muscle myostatin and follistatin or whether muscle fiber type-specific differences exist in the hypertrophic response to $\beta_{2}$-agonists. 
Animal studies have provided evidence that chronic $\beta_{2^{-}}$ adrenergic stimulation leads to a slow-to-fast fiber-type transition of the myosin heavy chain (MHC) isoforms, thus shifting the contractile properties of skeletal muscle $(76,81,82)$. The shift in MHC isoforms, along with gains in muscle mass, is associated with increased peak twitch and tetanic force (21, $82)$, increased maximal shortening velocity (21) and shortened time-to-peak tension (82). In humans, however, no studies have investigated whether chronic $\beta_{2}$-adrenergic stimulation affects MHC distribution, peak twitch force, and time-to-peak twitch force of skeletal muscle. Moreover, it has been suggested that the enhanced muscle force observed with chronic administration of $\beta_{2}$-agonists in humans may be related to central effects (45). $\beta_{2}$-Adrenoceptors are abundant in the brain and $\beta_{2}$-agonists have been shown to have antidepressant properties possibly through the serotonergic system (61). It has as such been speculated that $\beta_{2}$-agonists alters the degree of central activation during a maximal muscle contraction (45). It is therefore of interest to investigate whether chronic $\beta_{2}$ adrenergic stimulation affects the degree of voluntary activation during a superimposed maximal muscle contraction.

Chronic $\beta_{2}$-adrenergic stimulation has also been shown to modify oxidative and glycolytic properties of skeletal muscle in animals $(54,75)$. Thus studies in rodents have shown that oxidative capacity and capillary density are repressed following chronic treatment with the $\beta_{2}$-agonist clenbuterol $(28,78)$, which may be associated with compromised fatigue resilience during muscle activity $(22,66)$. In humans, on the other hand, chronic treatment with $\beta_{2}$-agonists was shown not to affect maximal oxygen consumption $\left(\dot{\mathrm{V}}_{2}{ }_{2 m a x}\right)$ and time to fatigue during incremental cycling in endurance athletes (30) and to prolong time to fatigue during submaximal cycling in trained men (16), suggesting that oxidative capacity remains unaltered or improved in humans. Moreover, chronic administration of $\beta_{2}$-agonists enhances power output during $30 \mathrm{~s}$ of maximal cycling in humans $(30,40,69)$, which may be related to increased expression of glycolytic enzymes of skeletal muscle. However, no studies have investigated whether chronic administration of $\beta_{2}$-agonists affects expression of oxidative and glycolytic enzymes in skeletal muscle of humans.

Thus the aim of the present study was to investigate underlying mechanisms by which chronic $\beta_{2}$-adrenergic stimulation enhances muscle force and power output during $30 \mathrm{~s}$ of maximal cycling in humans. Our hypothesis was that enhancements in muscle force and power output during maximal cycling induced by chronic $\beta_{2}$-adrenergic stimulation are primarily explained by skeletal muscle hypertrophy. A secondary aim was to examine whether muscle fiber type-specific differences exist in the hypertrophic response to chronic $\beta_{2}$-adrenergic stimulation in humans and how a potential hypertrophic response related to expression of muscle myostatin and follistatin.

\section{MATERIALS AND METHODS}

Subjects. Twenty healthy trained men were initially screened and included in the study. Before inclusion, subjects received oral and written information about the aims and contents of the study and possible risks involved including side effects of the study drug (terbutaline). Each subject gave his oral and written informed consent. A physician screened each subject for unknown cardiopulmonary disease with lung and heart stethoscopy and electrocardiography (ECG). Upon inclusion, subjects were randomly allocated in two groups, either an experimental group [terbutaline (TER)] or a control group [placebo (PLA)]. Two subjects did not complete the study (one from each group) due to inadequate time in their schedule. The subjects who completed the study were $23 \pm 1$ (TER) and $25 \pm 1$ (PLA) yr and $183 \pm 2$ (TER) and $178 \pm 2$ (PLA) $\mathrm{cm}$ in height and had a $\dot{\mathrm{V}}_{2 \text { max }}$ of $55 \pm 2$ (TER) and $57 \pm 2$ (PLA) $\mathrm{ml} \cdot \mathrm{min}^{-1} \cdot \mathrm{kg}^{-1}$. Subjects were recreationally active, engaging in running, biking, and light resistance training with a training volume of $4-8 \mathrm{~h} / \mathrm{wk}$. Subjects were told to refrain from competitive events for the entire study and not to change their daily physical activities and nutritional habits, which were recorded. The study was performed in accordance with the Helsinki II Declaration and was approved by the Ethics Committee of Copenhagen, Denmark (H-1-2012-090).

Study design. The study was designed as a randomized placebocontrolled trial with an experimental group (TER) and a control group (PLA). In TER, $\beta_{2}$-adrenoceptors were stimulated by administration of the selective $\beta_{2}$-agonist terbutaline (Bricanyl Retard; AstraZeneca, London, UK) in oral doses of $5 \mathrm{mg} / 30 \mathrm{~kg}$ body weight (bw) twice daily for $28 \pm 1$ days. In PLA, subjects received oral placebo tablets (lactose monohydrate/starch; PLA) for $28 \pm 1$ day. Study drugs were delivered to the subjects in bottles. The duration of treatment was based on previous studies showing that 3-4 wk of treatment with $\beta_{2}$-agonists is effective to enhance muscle force and power output during $30 \mathrm{~s}$ of maximal cycling in humans $(40,45,69)$. Since a previous study found no acute effect of $8 \mathrm{mg}$ oral terbutaline on muscle strength and performance (70), we chose a higher dose that has been shown to elicit a significant systemic response (32). Lactosemonohydrate/starch tablets were used as placebo. Study drugs were delivered by the regional pharmacy of Copenhagen. Both subjects and investigators were blinded to the treatments. Randomization was conducted in SPSS (IBM, Armonk, NY) by a technician who did not take part in any of the experimental procedures. Drug compliance of each subject was assessed by counting the number of unused tablets in the bottle after the intervention, comparing with the number of tablets in the bottle before the intervention. The number of tablets in the bottle before the intervention was random.

Experimental protocol. Before the start of the intervention, subjects met at the laboratory for two visits. At the first visit, subjects' body composition was measured by dual X-ray absorbance (DXA). After DXA, a biopsy was taken from the vastus lateralis muscle of the right thigh under local anesthesia (20 mg/ml Xylocain; AstraZeneca). Muscle biopsies were quickly frozen in liquid nitrogen and stored at $-80^{\circ} \mathrm{C}$ for later analysis. Subjects then warmed up for $10 \mathrm{~min}$ on a bike ergometer (Monark E839, Stockholm, Sweden), after which they performed an incremental exercise test starting at $150 \mathrm{~W}$ increasing by $30 \mathrm{~W}$ every min until time of fatigue. During the incremental test, subjects' pulmonary gas exchange was measured breath-by-breath with a gas analyzer system (Oxycon Pro, CareFusion, San Diego, CA) for determination of $\dot{\mathrm{V}}_{2 \max }$. Furthermore, subjects were accustomed to the experimental procedures conducted during the second visit. At the second visit, subjects' contractile properties of the quadriceps muscle were measured during maximal voluntary isometric contraction (MVC) with electrical percutaneous muscle stimulations delivered on top of the plateau of each MVC as well as $1 \mathrm{~s}$ following relaxation. Before measurements, subjects performed three submaximal contractions of a 3-s duration. Subjects then performed three MVCs of a 3- to 4-s duration, each interspersed by $90 \mathrm{~s}$ of recovery. MVC measurements were preceded by a 15 min warm-up at $150 \mathrm{~W}$ for $10 \mathrm{~min}$ and $200 \mathrm{~W}$ for $5 \mathrm{~min}$ on a bike ergometer. After MVC measurements, subjects completed $30 \mathrm{~s}$ of maximal cycling on a bike ergometer (Monark E839). During the test, subjects pedaled against a brake force of $0.90 \mathrm{~N} / \mathrm{kg}$ bw for $30 \mathrm{~s}$ as fast as possible. Subjects were instructed to remain seated throughout the entire test. Cadence and power output were recorded by a computer with a sampling frequency of $1 \mathrm{~Hz}$. After the test, peak power was calculated as the highest power achieved for five consecutive seconds and mean power as the average power output during the $30 \mathrm{~s}$ of maximal cycling. 
After the second visit, subjects received study drugs for a 4-wk intake. Subjects were instructed to ingest the study drugs twice daily during a meal (morning and afternoon). After the 4-wk period and $36-72 \mathrm{~h}$ of washout (terminal half-life of terbutaline: $\sim 4-6 \mathrm{~h}$ ), subjects reported to the laboratory again for two separate visits that were similar to those conducted before the drug intervention.

Subjects were told to abstain from alcohol, caffeine, nicotine, and strenuous exercise for $48 \mathrm{~h}$ before each laboratory visit.

Dual-energy X-ray absorptiometry. Subjects' whole-body composition was determined by DXA (Lunar DPX-IQ, Version 4.7 E; Lunar, Madison, WI). Subjects were placed in the scanner in supine position undressed and euhydrated. To reduce intraday variation, two scans at medium speed were performed according to the manufacturer's guidelines using medium research analysis software. The scanner was calibrated before scan, using daily calibration procedures (Lunar "System Quality Assurance"). All scans were conducted by the same hospital technician.

Contractile properties of the quadriceps muscle. For measurements of contractile properties of the quadriceps muscle, subjects were positioned on a chair with an adjustable chair back with thighs being parallel to the floor and right leg fixed in a knee joint angle of $90^{\circ}$ of flexion. To ensure that subjects remained in the same position during each measurement, three Velcro straps were tied around the chest, hips, and thighs. Subjects' body position was recorded and used for each measurement before and after the intervention. Isometric contraction force was recorded using a strain gauge (Tedea-Huntleigh) strapped around the right ankle just above the malleoli. Strain gauge signal was fed to an amplifier that was connected to a computer. Data were recorded at $1 \mathrm{kHz}$ in LabChart 7 (ADInstruments).

During and immediately after each MVC, superimposed percutaneous electrical muscle stimulations (58) were delivered to the vastus lateralis muscle and rectus femoris muscle by two self-adhesive electrodes (PALS Platinum $5 \times 9 \mathrm{~cm}$; Axelgaard Manufacturing, Lystrup, Denmark). Electrodes were placed on the skin $25 \%$ distal from spina iliaca anterior superior and $25 \%$ proximal from patella covering the vastus lateralis muscle and rectus femoris muscle. Muscle stimulations were produced by a constant current stimulator (Stimulator model DS7AH; Digitimer, Hertfordshire, UK) in rectangular pulses of $1 \mathrm{~ms}$. After placement of electrodes, stimulation intensity was progressively increased either until a plateau in peak twitch force was observed, until maximal stimulator output (999 mA) was achieved, or if subjects felt pain. Thus a stimulation intensity of $999 \mathrm{~mA}$, despite no plateau in peak twitch force, was considered the arbitrary maximum. With this stimulation intensity, we were able to activate $38 \pm 1 \%$ of peak MVC, being similar to that observed by Verges et al. (80) using electrical and magnetic femoral nerve stimulation at $100 \mathrm{~Hz}$. The same stimulation intensity was used for the same subject throughout the intervention. To determine degree of voluntary activation level, a single stimulation was delivered on top of the plateau of each MVC (48). A single stimulation was delivered 1 $\mathrm{s}$ following relaxation of each MVC to determine potentiated peak twitch force $(18,57)$. During MVC measurements, subjects received verbal encouragement with no visual feedback.

The following parameters were determined: $\mathrm{MVC}(\mathrm{N})$ : highest force during a MVC; peak twitch force $(\mathrm{N})$ : highest force during a potentiated single stimulation $1 \mathrm{~s}$ following relaxation from a MVC; half-relaxation time (ms): time from peak twitch force until force reached half of peak twitch force; and time-to-peak twitch force (ms): time from single stimulation until peak twitch force was reached.

Degree of voluntary activation level (VA) was calculated from the single twitches as described by Bachasson et al. (3) using the following equation:

$$
\mathrm{VA}=\left[1-\left(\mathrm{Tw}_{\mathrm{s}} / \mathrm{Tw}_{\mathrm{p}}\right)\right] \times 100
$$

where $T w_{\mathrm{s}}$ is the superimposed twitch delivered on top of the plateau of the MVC and $\mathrm{Tw}_{\mathrm{p}}$ is the potentiated twitch delivered following relaxation after a MVC. A correction was applied to the equation if the superimposed stimulation was delivered slightly before or after the peak MVC (77).

MHC composition in mixed muscle homogenate. MHC composition was determined from homogenate using gel electrophoresis (53). Muscle homogenate $(80 \mu \mathrm{l})$ was mixed with $200 \mu \mathrm{l}$ of sample buffer (10\% glycerol, $5 \%$ 2-mercaptoethanol and 2.3\% SDS, $62.5 \mathrm{mM}$ Tris, and $0.2 \%$ bromophenol blue at $\mathrm{pH} 6.8$ ), boiled in water at $100^{\circ} \mathrm{C}$ for 3 min and loaded $(10-40 \mu 1)$ on a SDS-PAGE gel [6\% polyacrylmide (100:1 acrylmid:bis-acrylmid), 30\% glycerol, $67.5 \mathrm{mM}$ Tris-base, $0.4 \% \mathrm{SDS}$, and $0.1 \mathrm{M}$ glycine]. Gels were run at $80 \mathrm{~V}$ for at least 42 $\mathrm{h}$ at $4{ }^{\circ} \mathrm{C}$ and $\mathrm{MHC}$ bands were made visible by staining with Coomassie. The gels were scanned (Lino-scan 1400 scanner, Heidelberg, Germany) and MHC bands were quantified densitometrically (Phoretix 1D, nonlinear, Newcastle, UK) as an average of the three loaded protein amounts.

Single fiber analysis. In total, 720 segments of single fibers (20 from each subjects' PRE and POST biopsies) were dissected free of any connective tissue under a microscope by pulling lengthwise using sharp needles and forceps. Each of the dissected fibers were then put in $0.5-\mathrm{ml}$ Eppendorf plastic tubes and stored at $-80^{\circ} \mathrm{C}$ until determination of fiber size.

Single fiber CSA was determined as described by Frontera and Larsson (25). Single fibers were incubated for $5 \mathrm{~min}$ in a fresh relaxing buffer containing the following (in $\mathrm{mM}$ ): $4 \mathrm{Mg}$-adenosine triphosphate, 1 free $\mathrm{Mg}^{2+}, 20$ imidazole, 7 ethyleneglycoltetraacetic acid (EGTA), 14.5 creatine phosphate, sufficient $\mathrm{KCl}$ to adjust the ionic strength to $180 \mathrm{mM}$, and a $\mathrm{pH}$ of 7.0. The concentration of free $\mathrm{Ca}^{2+}$ was $10^{-9} \mathrm{M}$. Individual single fibers were then placed under a microscope at $\times 500$ magnification. The microscope was connected to a camera (model VCC-2997; Sanyo) and interfaced to a computer, which allowed the single fibers to be viewed on a monitor during the measurements using the software Tema95 (v. 1.04; CheckVision, Hadsund, Denmark). Fiber diameter was measured at four different segments of each of the individual single fibers. Digitalized images of each measurement were stored on an external drive. Fiber CSA was calculated from the average diameter under the assumption that the fiber forms a cylindrical shape, without correction for swelling (5). After measurements, the fiber was frozen in liquid nitrogen and stored at $-80^{\circ} \mathrm{C}$ for later Western blotting.

Western blotting of single fibers. Before SDS-PAGE, $20 \mu \mathrm{l}$ of $6 \times$ Laemmli buffer $(0.7 \mathrm{ml}$ of $0.5 \mathrm{M}$ Tris base, $3 \mathrm{ml}$ glycerol, $0.93 \mathrm{~g}$ DTT, $1 \mathrm{~g}$ SDS, and $1.2 \mathrm{mg}$ bromophenol blue) diluted (1:3, vol:vol) in double distilled $\mathrm{H}_{2} \mathrm{O}\left(\mathrm{ddH}_{2} \mathrm{O}\right)$ was added to each single fiber and incubated for $1 \mathrm{~h}$ at room temperature. Five microliters $(\sim 0.25 \mathrm{mg} / \mathrm{ml}$ protein) of lysate were used for determination of expression of MHC I, MHC II, and sarcoplasmic reticulum $\mathrm{Ca}^{2+}$ ATPase isoform I (SERCAI) in each single fiber.

Individual single fiber lysates were loaded in 26-well TGX Criterion gels (4-15\% Tris.HCl; Bio-Rad Laboratories, Hercules, CA). Proteins were separated by SDS-PAGE (60 mA per gel and a maximum of $250 \mathrm{~V}$ ) for $\sim 60 \mathrm{~min}$. After SDS-PAGE, proteins were visualized using stain-free technology (ChemiDoc MP Imaging System; Bio-Rad Laboratories). The visualized stain-free signals were used to obtain an indication of the amount of protein in each lane and used to normalize for loading between the fibers. Afterwards, gels were transferred (TransBlotTurbo; Bio-Rad Laboratories) to a polyvinylidene difluoride (PVDF) membrane (Transfer Pack; Bio-Rad Laboratories) for $7.5-10 \mathrm{~min}$ at $2.5 \mathrm{~mA}$ per gel and $20-25 \mathrm{~V}$. Membranes were blocked in Tris-buffered saline including $0.1 \%$ Tween-20 (TBST) with $2 \%$ milk for $30 \mathrm{~min}$ and then incubated in primary antibodies (MHC I: no. A4.840; Developmental Studies Hybridoma Bank, University of Iowa; MHC II: no. A4.74; Developmental Studies Hybridoma Bank; SERCAI: no. MA3-912, Thermo Fisher Scientific), overnight at $5^{\circ} \mathrm{C}$. After two washes in TBST, membranes were incubated for $1 \mathrm{~h}$ in horseradish peroxidase-conjugated secondary antibody (DAKO, Copenhagen, Denmark) diluted 1:5000 in TBST with 2\% milk. Membranes were then washed in 
TBST (3 times, for $15 \mathrm{~min}$ each), after which bands were visualized using chemiluminescent detection (Super Signal West FemtoMaximumSensitivity Substrate; ThermoScientific, Rockford, IL) and images were collected on the ChemiDoc MP Imaging System. Band intensities were quantified using Image Lab (Image Lab v. 4.0; Bio-Rad Laboratories).

Data treatment of single fibers. Single fibers were divided according to their expression of either MHC I $(n=354)$ or MHC II $(n=$ 266). Fibers were excluded from further analysis if they coexpressed MHC I and MHC II $(n=32)$, if no signal was detected $(n=46)$, or if the individual fiber was too short $(<1 \mathrm{~mm})(n=22)$. Thus 620 single fibers were included in the data analysis.

Western blotting of mixed muscle lysate. We also determined specific expression of various proteins in mixed muscle homogenate. Two milligrams of dry weight muscle tissue were dissected free from connective tissue was homogenized on ice in a fresh buffer $(10 \%$ glycerol, $20 \mathrm{mM}$ Na-pyrophosphate, $150 \mathrm{mM} \mathrm{NaCl}, 50 \mathrm{mM}$ HEPES, $1 \%$ Nonidet P-40, $20 \mathrm{mM} \beta$-glycerophosphate, $10 \mathrm{mM} \mathrm{NaF}, 2 \mathrm{mM}$ PMSF, $1 \mathrm{mM}$ EDTA, 1mM EGTA, $10 \mathrm{~g} / \mathrm{ml}$ aprotinin, $10 \mathrm{~g} / \mathrm{ml}$ leupeptin, and $3 \mathrm{mM}$ benzamidine) with a Polytron 3100 (Kinematica) for $30 \mathrm{~s}$. Samples were rotated end-over-end for $1 \mathrm{~h}$ at $4^{\circ} \mathrm{C}$ before being centrifuged for $30 \mathrm{~min}$ at $17,500 \mathrm{~g}$ at $4^{\circ} \mathrm{C}$. Lysate was collected as the supernatant and protein concentrations were determined by ELISA using BSA standards (Pierce Reagents). Before SDS-PAGE, the lysates were diluted in a $6 \times$ sample buffer $(0.5 \mathrm{M}$ Tris-base, DTT, SDS, glycerol, and bromphenol blue) to a final protein concentration of $2 \mu \mathrm{g} / \mathrm{ml}$. The procedures of SDS-PAGE, transfer, incubation of membranes in antibodies, and visualization were the same as described for the single fiber analysis above. Samples from the same subject were loaded next to each other on the same gel. Primary antibodies used were cytochrome $c$ oxidase subunit IV (COX4; no. sc-58348; Santa Cruz Biotechnology, Santa Cruz, CA), citrate synthase (CS; no. ab96600; abcam, Cambridge, UK), dihydropyridine receptor (DHPR; no. ab2864; abcam), FXYD1 (no. 13721-1-AP; Proteintech Group), growth differentiation factor-8 (myostatin; no. sc-6885-R; Santa Cruz Biotechnology), hydroxyacyl CoA dehydrogenase (HAD; no. ab54477; abcam), follistatin (no. sc-30194; Santa Cruz Biotechnology), lactate dehydrogenase (LDH; no. sc-33781; Santa Cruz Biotechnology), $\mathrm{Na}^{+} / \mathrm{K}^{+}$-ATPase subunit $\alpha_{2}(07-674$; Merck Millipore), $\mathrm{Na}^{+} / \mathrm{K}^{+}$-ATPase subunit $\alpha_{1}$ (no. 05-369; Merck Millipore), $\mathrm{Na}^{+} / \mathrm{K}^{+}$-ATPase subunit $\beta_{1}$ (no. MA3-930; Thermo Fisher Scientific), OXPHOS (no. MS601; MitoSciences, OR), pyruvate dehydrogenase (PDH; no. sc-377092; Santa Cruz Biotechnology), phosphofructokinase (PFK; no. sc-166722; Santa Cruz Biotechnology), ryanodine receptor 1 (RyR1; no. R129; SigmaAldrich, St. Louis, MO), sarcoplasmic reticulum $\mathrm{Ca}^{2+}$ ATPase isoform I (SERCAI; no. MA3-912; Thermo Fisher Scientific, MA), and sarcoplasmic reticulum $\mathrm{Ca}^{2+}$ ATPase isoform II (SERCAII; no. sc-8095; Santa Cruz Biotechnology).

Statistical analysis. Sample size was determined for the primary response variable (MVC) for a mixed model design of this pre-post parallel-groups controlled trial. The effect size and SD were chosen based on a study by Martineau et al. (45) showing that the difference in change of voluntary quadriceps muscle strength between oral salbutamol and placebo after 3 wk of administration was $17 \%$ with a within-subject SD of $8.7 \%$ (45). The maximum rates of statistical errors were defined as $5 \%$ for type I $(\alpha)$ and $20 \%$ for type II $(\beta)$. Sample size calculation revealed that at least nine subjects should be included in each group. With a risk of having a dropout, we included 10 subjects in each group.

Statistical analysis was performed with SPSS 22 software (IBM). Data were tested for normality using the Shapiro-Wilk test and Q-Q plots. Data were normally distributed and are presented as means \pm SE unless specified otherwise. Differences between the groups before the start of the intervention were tested with an unpaired $t$-test. To determine changes with the intervention, linear mixed modeling was used with treatment and time as fixed factors and subjects as a random factor. The essence of the analysis was to compare the interaction (treatment $\times$ time) between TER and PLA with a measure of change for a dependent variable with the intervention. The main outcome of the linear mixed model was thus a difference in mean change between TER and PLA with the intervention as described by Hopkins (29). Also, in case of a significant interaction, within-group changes with the intervention were determined. Multiple linear regression using the backward method was used to estimate the contribution of mechanism variables for a given dependent variable response with the intervention in TER. The coefficient of determination of the backward multiple linear regression is presented as the $R$ square and adjusted $R$ square with corresponding results from the ANOVA. The stepping method criteria were defined as a probability of $F$ at 0.05 for entry and 0.15 for removal. To determine predictors of change in MVC with the intervention in TER, the following predictors were included as independent variables in the model $(21,45,66)$ : change in CSA of MHC I and MHC II fibers, MHC isoform distribution, and degree of voluntary activation level of the quadriceps muscle with the intervention. For change in peak and mean power output during $30 \mathrm{~s}$ of maximal cycling with the intervention in TER, the best model fit approach was used in that peak and mean power output may rely on several factors. Since it has been speculated that training status may affect the chronic response to $\beta_{2}$-agonists $(30,59,69)$, we also determined whether subjects' baseline characteristics in MHC isoform distribution, habitual training volume, and $\dot{\mathrm{V}}_{2 \max }$ could predict change in MVC, peak and mean power output during $30 \mathrm{~s}$ of maximal cycling, and muscle hypertrophy with the intervention in TER. The level of significance for all analysis was defined as $P \leq 0.05$.

\section{RESULTS}

Side effects, drug compliance, and habitual training volume. Side effects were reported by seven subjects in TER and by three in PLA. Side effects in TER included tremor $(n=7)$, tachycardia $(n=4)$, restlessness $(n=3)$, and headache $(n=1)$ during the first days of treatment that surpassed within the first week of treatment. In PLA, side effects included tachycardia $(n=2)$, nausea $(n=1)$, and restlessness $(n=1)$. Drug compliance was $92 \pm 2$ and $94 \pm$ $2 \%$ in TER and PLA, respectively. Subjects' habitual training volume did not change with the intervention, being $4.9 \pm 0.4$ and $4.8 \pm 0.3 \mathrm{~h} / \mathrm{wk}$, before and after the intervention in TER, respectively, and $5.1 \pm 0.3$ and $5.1 \pm 0.3 \mathrm{~h} / \mathrm{wk}$ in PLA, respectively.

Contractile properties of the quadriceps muscle. MVC before and after the intervention in TER and PLA are presented in Fig. 1. No differences were observed in the contractile properties of quadriceps muscle between the groups before the intervention. Significant interactions (treatment $\times$ time) were observed for MVC $(P \leq 0.01)$ and peak twitch force $(P \leq$ $0.01)$ between TER and PLA with the intervention. TER increased MVC by $97 \pm 29 \mathrm{~N}$ and peak twitch force by $67 \pm$ $14 \mathrm{~N}$ compared with PLA (Fig. 1, $A$ and $B$ ). Degree of voluntary activation level, time-to-peak twitch force, and halfrelaxation time did not change with the intervention in either group (Table 1).

Power output during 30 s of maximal cycling and $\dot{V}_{o_{2 \max }}$ and time to fatigue during incremental cycling. Peak and mean power during $30 \mathrm{~s}$ of maximal cycling as well as $\dot{\mathrm{V}}_{2}$ max and time to fatigue during incremental cycling in TER and PLA before and after the intervention are presented in Table 2. No differences were observed between the groups before the intervention. Significant interactions (treatment $\times$ time) were observed for peak power $(P \leq 0.01)$ and mean power $(P \leq$ $0.01)$ between TER and PLA with the intervention. Peak power and mean power increased by $32 \pm 8$ and $25 \pm 9 \mathrm{~W}$, 

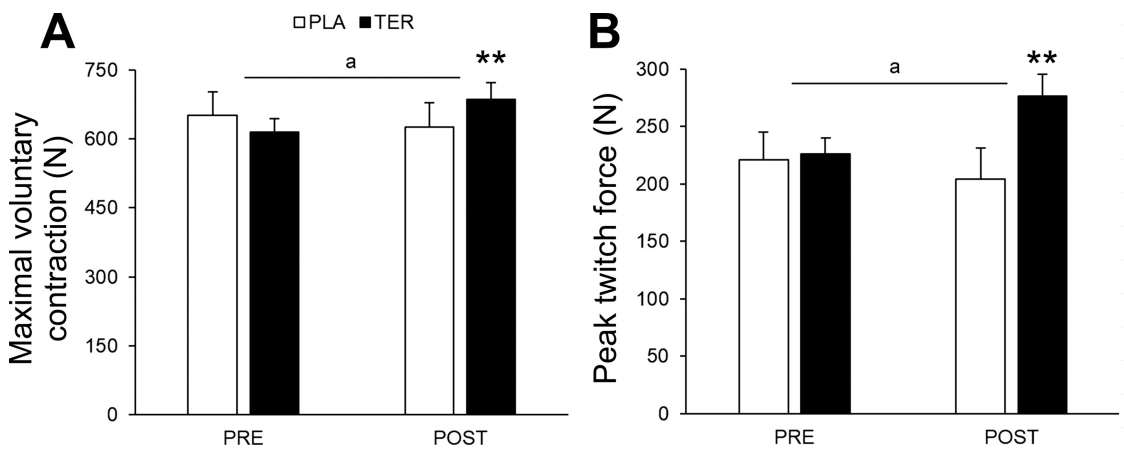

\begin{abstract}
Fig. 1. Maximal voluntary contraction $(A)$ and peak twitch force $(B)$ of the quadriceps muscle before (PRE) and after (POST) 4 wk of oral administration of either terbutaline [TER; $5 \mathrm{mg} / 30 \mathrm{~kg}$ body weight (bw) twice daily; $n=9$ ] or placebo (PLA; $n=9$ ). Data are presented as means \pm SE. ${ }^{\text {a Significant }}(P \leq 0.01)$ interaction (treatment $\times$ time) between TER and PLA with the intervention. **Different $(P \leq 0.01)$ from PRE (within-group).
\end{abstract}

respectively, with the intervention in TER compared with PLA. No changes were observed in $\dot{\mathrm{V}}_{2}$ max and time to fatigue during incremental cycling with the intervention in either group (Table 2).

Body composition. Body composition in TER and PLA before and after the intervention and within-group change scores are presented in Table 3. No differences were observed in body composition between the groups before the intervention. Significant interactions (treatment $\times$ time) were observed for lean body mass $(P \leq 0.05)$ and fat mass $(P \leq 0.05)$ between TER and PLA with the intervention. TER increased lean body mass by $1.95 \pm 0.8 \mathrm{~kg}$ and reduced fat mass by $0.97 \pm 0.44 \mathrm{~kg}$ compared with PLA with the intervention. Change in lean body mass with the intervention is presented in Fig. 2. Body mass and bone mineral density did not change with the intervention in either group.

MHC isoform distribution and single fiber CSA. MHC isoform distribution and single fiber CSA in TER and PLA before and after the intervention are presented in Table 4. MHC isoform distribution and single fiber CSA did not differ between the groups before the intervention. MHC isoform distribution did not change with the intervention in either group, whereas significant interactions (treatment $\times$ time) were observed for single fiber CSA of MHC I $(P \leq 0.05)$ and MHC II $(P \leq 0.05)$ fibers between TER and PLA with the intervention. Single fiber CSA increased by $1,205 \pm 558 \mu^{2}$ in MHC I fibers and by $1,277 \pm 595 \mu \mathrm{m}^{2}$ in MHC II fibers with the intervention in TER compared with PLA. Change in single fiber CSA of MHC I and MHC II fibers with the intervention is presented in Fig. 2.

Muscle $\mathrm{Na}^{+} / \mathrm{K}^{+}$-ATPase subunits, $\mathrm{Ca}^{2+}$ handling proteins, and monocarboxylate transporter 1 . Changes in expression of muscle proteins involved in ion handling and lactate clearance in TER and PLA before and after the intervention are presented in Fig. 3. Significant interactions (treatment $\times$ time) were observed in expression of $\mathrm{Na}^{+} / \mathrm{K}^{+}$-ATPase subunits $\alpha_{2}$ and $\beta_{1}$ and FXYD1 between TER and PLA with the interven- tion. In TER, expression of $\mathrm{Na}^{+} / \mathrm{K}^{+}$-ATPase subunits $\alpha_{2}$ and $\beta_{1}$ and FXYD1 was higher $(P \leq 0.05)$ after the intervention compared with before, whereas no change was observed in PLA (Fig. 3, B-D). No changes were observed in expression of $\mathrm{Na}^{+} / \mathrm{K}^{+}$-ATPase subunit $\alpha_{1}$ with the intervention in either group (fig. $3 A$ ).

Significant interactions (treatment $\times$ time) were observed in expression of DHPR, SERCAI and monocarboxylate transporter 1 (MCT1) between TER and PLA with the intervention. In TER, expression of DHPR $(P \leq 0.01)$, SERCAI $(P \leq 0.05)$, and MCT1 $(P \leq 0.01)$ was higher after the intervention compared with before, whereas no change was observed in PLA (Fig. 3, $E-I$ ). Expression of RyR1 and SERCAII did not change with the intervention in either group (Fig. 3, $F$ and $H$ ).

Muscle glycolytic and oxidative enzymes. Changes in expression of muscle glycolytic and oxidative enzymes in TER and PLA before and after the intervention are presented in Fig. 4. Significant interactions (treatment $\times$ time) were observed in expression of PDH and LDH between TER and PLA with the intervention. In TER, expression of PDH $(P \leq 0.05)$ and $\mathrm{LDH}$ $(P \leq 0.01)$ was higher after the intervention compared with before, whereas no changes were observed in PLA (Fig. 4, B and $C$ ). No changes were observed in expression of CS, PFK, HAD, COX4, and OXPHOS complex III-V with the intervention in either group (Fig. 4, $A-I$ ).

Muscle follistatin and myostatin. Changes in expression of muscle follistatin and myostatin in TER and PLA before and after the intervention are presented in Fig. 5. A significant interaction (treatment $\times$ time) was observed in expression of follistatin between TER and PLA with the intervention. In TER, expression of follistatin was higher $(P \leq 0.01)$ after the intervention compared with before, whereas no changes were observed in PLA (fig. 5A). Expression of myostatin did not change with the intervention in either group (Fig. $5 B$ ).

Predictors of change in MVC and power output during 30 $s$ of maximal cycling with the intervention in TER. Multiple linear regression $\left[F(4,4)=7.1, P \leq 0.05, R^{2}=0.88\right.$,

Table 1. Contractile properties of the quadriceps muscle PRE and POST 4 wk of oral administration of either TER or PLA in trained men

\begin{tabular}{|c|c|c|c|c|}
\hline & \multicolumn{2}{|c|}{$\operatorname{TER}(n=9)$} & \multicolumn{2}{|c|}{ PLA $(n=9)$} \\
\hline & PRE & POST & PRE & POST \\
\hline Degree of voluntary activation level, \% & $92.7 \pm 1.9$ & $94.1 \pm 1.4$ & $91.1 \pm 1.5$ & $90.4 \pm 1.8$ \\
\hline Time-to-peak twitch force, ms & $73.2 \pm 1.4$ & $69.0 \pm 1.7$ & $74.7 \pm 2.3$ & $74.6 \pm 2.7$ \\
\hline Half-relaxation time, ms & $26.0 \pm 2.2$ & $27.6 \pm 4.0$ & $25.6 \pm 4.3$ & $23.8 \pm 1.8$ \\
\hline
\end{tabular}

Data are presented as means \pm SE. PRE, before; POST, after; TER, terbutaline; PLA, placebo. 
Table 2. Peak power and mean power during $30 \mathrm{~s}$ of maximal cycling as well as $\dot{V}_{o_{\text {max }}}$ and time of fatigue during incremental cycling PRE and POST 4 wk of oral administration of either TER or PLA in trained men

\begin{tabular}{|c|c|c|c|c|}
\hline & \multicolumn{2}{|c|}{$\operatorname{TER}(n=9)$} & \multicolumn{2}{|c|}{$\operatorname{PLA}(n=9)$} \\
\hline \multicolumn{5}{|c|}{$30 \mathrm{~s}$ of maximal cycling } \\
\hline Mean power,* W & $646 \pm 14$ & $664 \pm 15 \dagger$ & $693 \pm 21$ & $686 \pm 17$ \\
\hline \multicolumn{5}{|l|}{ Incremental cycling } \\
\hline$\dot{\mathrm{V}}_{\mathrm{O}_{\max }}, 1 / \mathrm{min}$ & $4.3 \pm 0.1$ & $4.2 \pm 0.1$ & $4.4 \pm 0.1$ & $4.5 \pm 0.1$ \\
\hline Time of fatigue, $\mathrm{s}$ & $406 \pm 20$ & $419 \pm 23$ & $441 \pm 24$ & $487 \pm 15$ \\
\hline
\end{tabular}

Data are presented as means \pm SE. $\dot{V}_{O_{\max }}$, maximal oxygen consumption. *Significant $(P \leq 0.01)$ interaction (treatment $\times$ time) between TER and PLA with the intervention. $\dagger$ Different $(P \leq 0.05)$ from PRE (within-group). $\neq$ Different $(P \leq 0.01)$ from PRE (within-group).

$R^{2}$ adjusted $\left.=0.75\right]$ showed that change in CSA of MHC I and MHC II fibers was the only significant $(P \leq 0.01)$ predictor for change in MVC with the intervention in TER, whereas change in MHC isoform distribution $(P=0.70)$ and degree of voluntary activation level $(P=0.18)$ did not contribute significantly to the model.

Change in leg lean body mass, MHC IIa isoform distribution, and $\mathrm{LDH}$ predicted change in peak power with the intervention in TER $\left[F(3,5)=21.9, P \leq 0.01, R^{2}=0.93, R^{2}\right.$ adjusted $\left.=0.89\right]$ in the multiple linear regression, with all three variables adding significantly $(P \leq 0.05)$ to the model. For mean power output, change in leg lean body mass, SERCAI, MHC IIa isoform distribution, and OXPHOS complex $\mathrm{V}$ predicted change in mean power with the intervention in TER $[F(4,4)=15.9, P \leq 0.01$, $\left.R^{2}=0.94, R_{\text {adjusted }}^{2}=0.88\right]$, with all four variables adding significantly $(P \leq 0.05)$ to the model.

Subjects' MHC isoform distribution, habitual training volume, and $\dot{\mathrm{V}}_{2}$ max , at baseline (PRE) could not predict change in MVC, power output during $30 \mathrm{~s}$ of maximal cycling, lean body mass, and CSA of MHC I and MHC II fibers with the intervention in TER (all $P \geq 0.10$ ).

\section{DISCUSSION}

The novel findings of the present study were that enhancements in muscle force and power output during $30 \mathrm{~s}$ of maximal cycling induced by chronic $\beta_{2}$-adrenergic stimulation in humans primarily are explained by skeletal muscle hypertrophy. In addition, that change in amount of MHC IIa isoforms and in expression of proteins involved in lactate production (LDH), $\mathrm{Ca}^{2+}$ uptake (SERCAI), and oxidative phosphorylation (OXPHOS complex V) of skeletal muscle mediated by chronic $\beta_{2}$-adrenergic stimulation were complimentary mechanisms for enhancements in power output during $30 \mathrm{~s}$ of maximal cycling.
In the present study, chronic $\beta_{2}$-adrenergic stimulation with terbutaline increased isometric muscle force of the quadriceps (MVC and peak twitch force) and power output during $30 \mathrm{~s}$ of maximal cycling. Although several studies have described that treatment with $\beta_{2}$-agonists increases muscle force and power output during maximal cycling in humans $(10,30,40,45,69)$, the present study is first to elucidate the underlying mechanisms. Our observations suggest that the increased muscle force induced by chronic $\beta_{2}$-adrenergic stimulation can be explained by skeletal muscle hypertrophy rather than changes in fiber-type composition or degree of voluntary activation level of skeletal muscle. This was also supported by multiple regression analysis, in which increase in MVC primarily was explained by hypertrophy of MHC I and MHC II fibers in response to terbutaline. Observations in animals also indicate that hypertrophy is the determining factor for the increased muscle force associated with chronic $\beta_{2}$-adrenergic stimulation rather than fiber-type transitions of the MHC isoforms, as treatment with $\beta_{2}$-agonists increases absolute tension while specific force, i.e., muscle force per CSA, remains unchanged $(21,26,66)$. For enhancements in power output during $30 \mathrm{~s}$ of maximal cycling induced by terbutaline in the present study, regression analysis showed that change in leg lean body mass could predict $66 \%$ (Pearson's correlation: $R^{2}=0.66, P \leq$ 0.01 ) of change in peak power output. Notably, with inclusion of change in amount of MHC IIa isoforms and expression of $\mathrm{LDH}$, along with change in leg lean body mass, in a multiple linear regression, $89 \%$ of change in peak power output could be predicted with the intervention in TER. Thus the present observations indicate that muscle hypertrophy is the primary mechanism by which chronic treatment with $\beta_{2}$-agonists enhances peak power during $30 \mathrm{~s}$ of maximal cycling, with change in amount of MHC IIa isoforms and LDH expression as complimentary mechanisms. For change in mean power, $88 \%$

Table 3. Body composition PRE and POST 4 wk of oral administration of either TER or PLA in trained men

\begin{tabular}{|c|c|c|c|c|c|c|}
\hline & \multicolumn{3}{|c|}{ TER $(n=9)$} & \multicolumn{3}{|c|}{$\operatorname{PLA}(n=9)$} \\
\hline Body mass, kg & $77.6 \pm 1.7$ & $77.8 \pm 1.9$ & $0.3 \pm 0.7$ & $76.9 \pm 2.8$ & $76.3 \pm 2.8$ & $-0.7 \pm 0.4$ \\
\hline Fat mass, ${ }^{*} \mathrm{~kg}$ & $9.7 \pm 1.0$ & $8.2 \pm 0.7 \dagger$ & $-1.4 \pm 0.6 \S$ & $7.6 \pm 0.9$ & $7.2 \pm 1.3$ & $-0.4 \pm 0.6$ \\
\hline Bone mineral density, $\mathrm{g} / \mathrm{cm}^{2}$ & $1.36 \pm 0.02$ & $1.37 \pm 0.02$ & $0.01 \pm 0.00$ & $1.26 \pm 0.02$ & $1.27 \pm 0.02$ & $0.01 \pm 0.00$ \\
\hline
\end{tabular}

Data are presented as means \pm SE. *Significant $(P \leq 0.05)$ interaction (treatment $\times$ time) between TER and PLA with the intervention. $\dagger$ Different $(P \leq 0.05)$ from PRE (within-group). $\ddagger$ Different $(P \leq 0.01)$ from PRE (within-group). §Different $(P \leq 0.01)$ from PLA (between-groups). 


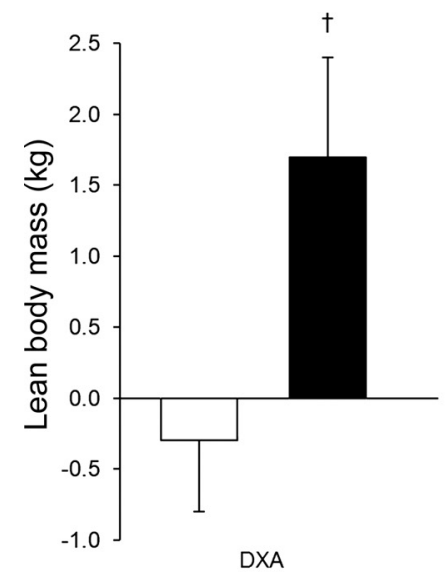

DXA
口PLA $\mathbf{\square T E R}$

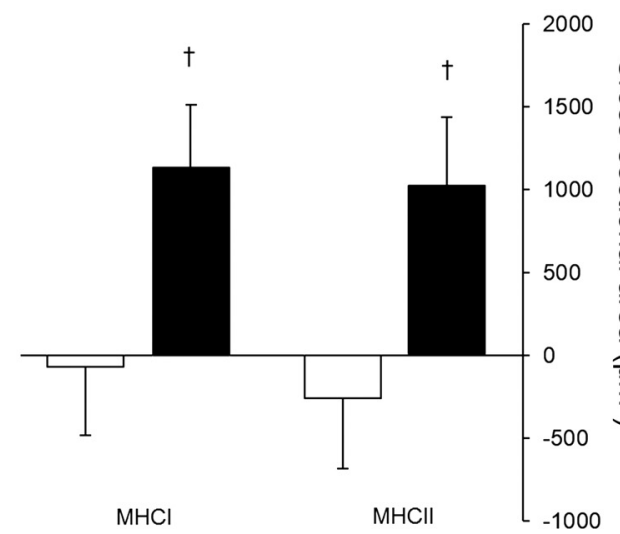

Fig. 2. Change in lean body mass measured by dual $\mathrm{X}$-ray absorbance (DXA) and change in cross-sectional area of myosin heavy chain (MHC) I and II single fibers of the vastus lateralis muscle with 4 wk of oral administration of either TER $(5 \mathrm{mg} / 30 \mathrm{~kg}$ bw twice daily; $n=9)$ or PLA $(n=9)$. Data are presented as means \pm SE. 'Different $(P \leq 0.05)$ from PLA (between-groups). could be explained by change in leg lean body mass, MHC IIa, SERCAI, and OXPHOS complex $\mathrm{V}$ in multiple regression analysis with the intervention in TER. While it has been speculated that muscle fiber-type composition and training status may influence the chronic response to $\beta_{2}$-agonists in humans $(30,59,69)$, we observed no indication that baseline characteristics in MHC distribution, habitual training volume, or $\dot{\mathrm{V}}_{2 \max }$ of the included subjects affected response to terbutaline for MVC and power output during maximal cycling. This observation is also consistent with that observed by Le Panse et al. (39), in which 3 wk of oral administration of salbutamol enhanced peak power output during $30 \mathrm{~s}$ of maximal cycling to a similar extent in trained and untrained subjects (40).

The observation that muscle hypertrophy is the primary mechanism by which $\beta_{2}$-agonists enhance peak power output during maximal cycling is not surprising, since resistance training also enhances peak power output during maximal exercise $(38,68)$. Thus a larger muscle mass may allow a higher force development during each stroke of maximal cycling. In agreement, Sanchez et al. (69) observed that the enhanced power output during $30 \mathrm{~s}$ of maximal cycling induced by oral salbutamol was attributed to a $14 \%$ higher force at given velocities (70-200 rpm). For the complimentary mechanisms of mean power output observed in the present study, the increased expression of SERCAI induced by chronic treatment of terbutaline may have augmented $\mathrm{Ca}^{2+}$ uptake function of the sarcoplasmic reticulum. A higher content of SERCAI could potentially accelerate $\mathrm{Ca}^{2+}$ reuptake and hence muscle relaxation between each stroke during maximal cy- cling. As such, Seebacher et al. (71) observed that SERCA activity is important in maintaining $\mathrm{Ca}^{2+}$ availability of the sarcoplasmic reticulum for subsequent release during maximal muscle activity. Thus the enhancing effects of chronic administration of $\beta_{2}$-agonists on maximal cycling may be attributed to both increased force production and accelerated relaxation respectively mediated by hypertrophy and augmented $\mathrm{Ca}^{2+}$ handling function of skeletal muscle.

In rodents, chronic clenbuterol treatment has been shown to compromise muscle fatigue resilience $(22,66,73)$, which may be attributed to depressed oxidative capacity $(13,28,43)$ and reduced capillary density (78). In the present study, however, we observed no effect of terbutaline on $\dot{\mathrm{V}}_{2}$ max and time to fatigue during incremental exercise, which is consistent with that observed in endurance athletes after 2-wk treatment of oral salbutamol (30). Collomp et al. (16) even observed that 3 -wk treatment of oral salbutamol increased time to fatigue during submaximal exercise in trained men. Our muscle protein data also showed no indication of depressed oxidative capacity, since no changes were observed in CS, HAD, COX4, and OXPHOS complexes III-V with terbutaline. In fact, we observed that terbutaline increased muscle expression of PDH as well as LDH and MCT1, which is essential for lactate production and clearance during exercise. Likewise, muscle expression of $\mathrm{Na}^{+}-\mathrm{K}^{+}$-ATPase subunits $\alpha_{2}$ and $\beta_{1}$ and FXYD1 was higher after terbutaline treatment in the present study. Since maximal muscle activity is associated with large ion shifts of $\mathrm{K}^{+}$and $\mathrm{Na}^{+}$that influence excitation-contraction coupling (47), the higher content of $\mathrm{Na}^{+} / \mathrm{K}^{+}$-ATPase subunits $\alpha_{2}$ and $\beta_{1}$ and FXYD1 observed with terbutaline in the present study

Table 4. MHC isoform distribution and CSA of MHC I and MHC II fibers PRE and POST 4 wk of oral administration of either TER or PLA in trained men

\begin{tabular}{|c|c|c|c|c|}
\hline & \multicolumn{2}{|c|}{ TER $(n=9)$} & \multicolumn{2}{|c|}{$\operatorname{PLA}(n=9)$} \\
\hline \multicolumn{5}{|l|}{ Fiber CSA } \\
\hline MHC II fibers, ${ }^{*} \mu \mathrm{m}^{2}(n=266)$ & $7,936 \pm 187$ & $8,955 \pm 183 \dagger$ & $8,611 \pm 193$ & $8,353 \pm 194$ \\
\hline \multicolumn{5}{|l|}{ MHC isoforms } \\
\hline MHC I, \% & $55 \pm 5$ & $52 \pm 5$ & $56 \pm 4$ & $53 \pm 3$ \\
\hline MHC IIa, \% & $43 \pm 4$ & $46 \pm 4$ & $43 \pm 4$ & $44 \pm 2$ \\
\hline
\end{tabular}

Data are presented as means \pm SE. MHC, myosin heavy chain; CSA, cross-sectional area. * Significant $(P \leq 0.05)$ interaction (treatment $\times$ time) between TER and PLA with the intervention. $\dagger$ Different $(P \leq 0.05)$ from PRE (within-group). $\ddagger$ Different $(P \leq 0.01)$ from PRE (within-group). 
A

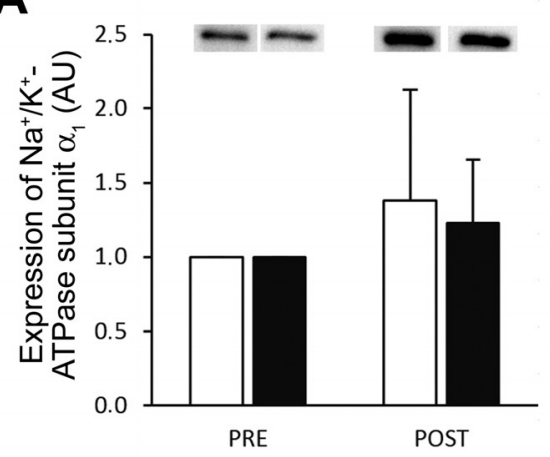

D

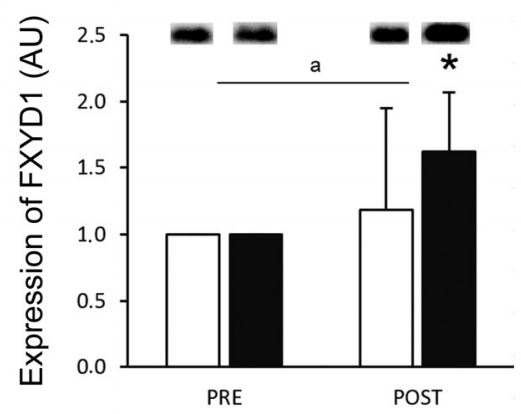

G

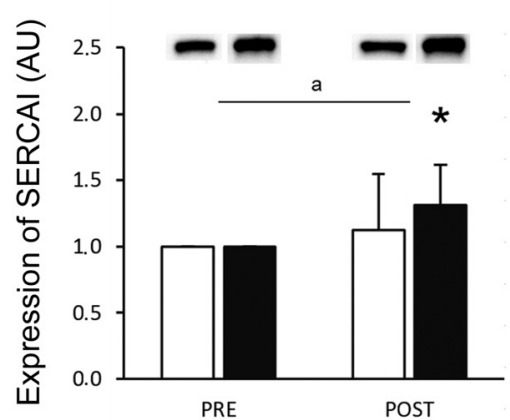

B

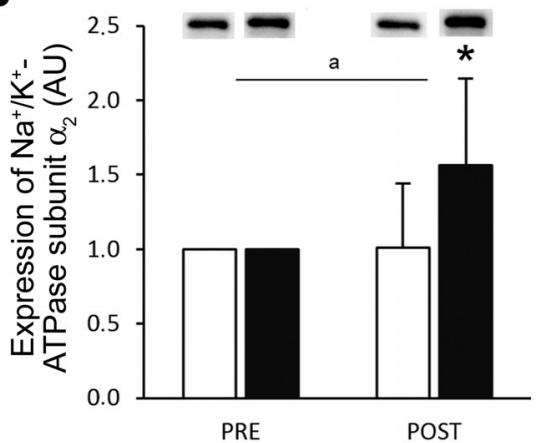

E

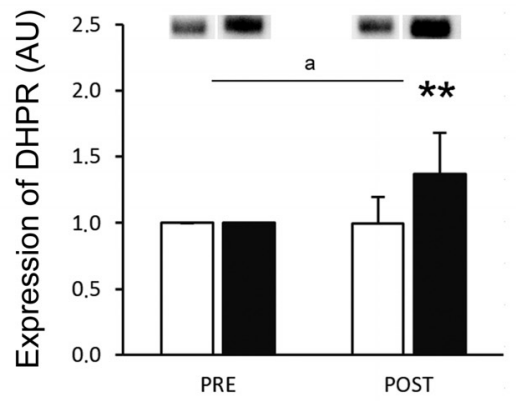

H

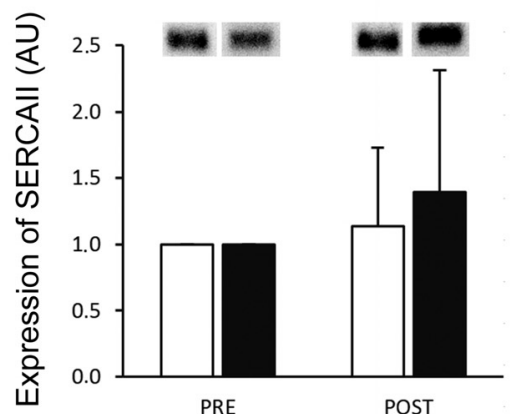

C

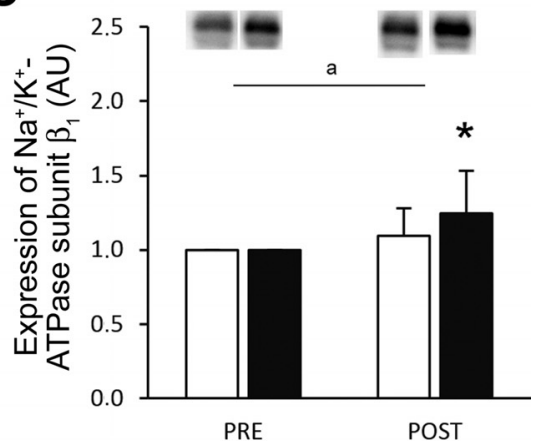

F

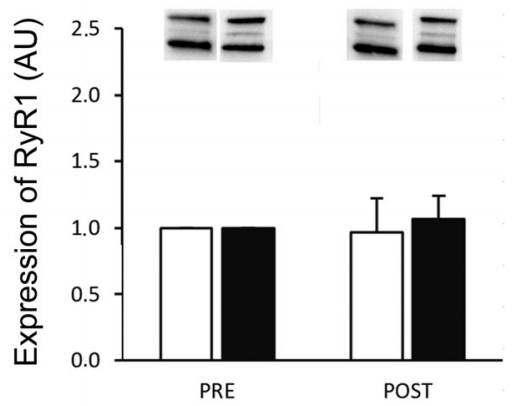

I

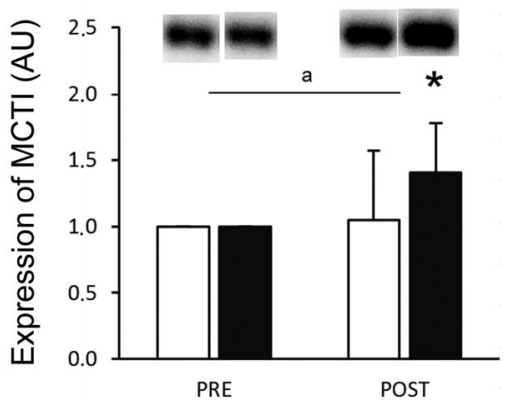

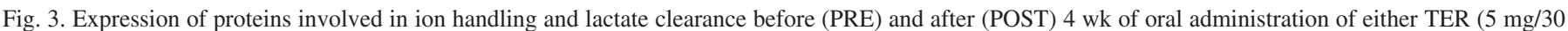

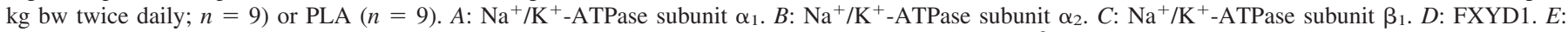

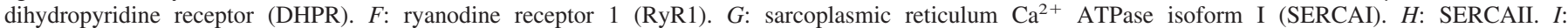

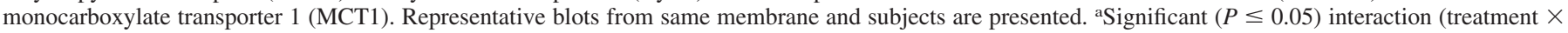

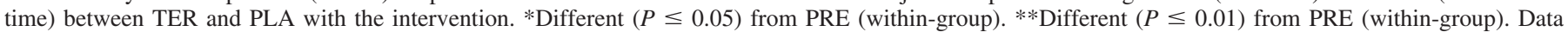
presented as mean $\pm \mathrm{SD}$. Values are relative to PRE.

could help counteract contraction-induced accumulation of extracellular $\mathrm{K}^{+}$and thus prevent loss of force development caused by membrane inexcitability (15). Taken together, it does therefore not appear that chronic $\beta_{2}$-adrenergic stimulation compromises oxidative capacity and fatigue resilience in humans. Our observations rather support the proposition made by Pearen et al. (54) that the responses to $\beta_{2}$-adrenergic stimulation in skeletal muscles in some ways are comparable to those observed with exercise training $(38,47,68)$. The discrepancies between the detrimental effects of chronic $\beta_{2^{-}}$ adrenergic stimulation on muscle performance in animal studies compared with that observed in humans could be related to the markedly higher doses administered to animals. While clenbuterol compromises fatigue resilience in animals, low-dose administration of formoterol was found to have no effect on muscle fatigability in mice despite of marked hypertrophy (26).

To our knowledge the present study is first to show a hypertrophic effect of $\beta_{2}$-adrenergic stimulation in skeletal muscle fibers of humans. Hypertrophy was not only evident in single fibers of the vastus lateralis muscle but also by a $1.7-\mathrm{kg}$ gain in lean body mass with the intervention in TER. Although these observations are comparable to those observed in animals $(34,44)$, previous human studies did not find hypertrophic effects of chronic administration of $\beta_{2}$-agonists $(10,12,39,40$, 45). However, in these studies, only whole body composition was measured, whereas animal studies along with the present determined CSA of skeletal muscle fibers $(9,21,66,81)$. Studies in humans have shown that the relative hypertrophic response to resistance training and protein supplementation is 

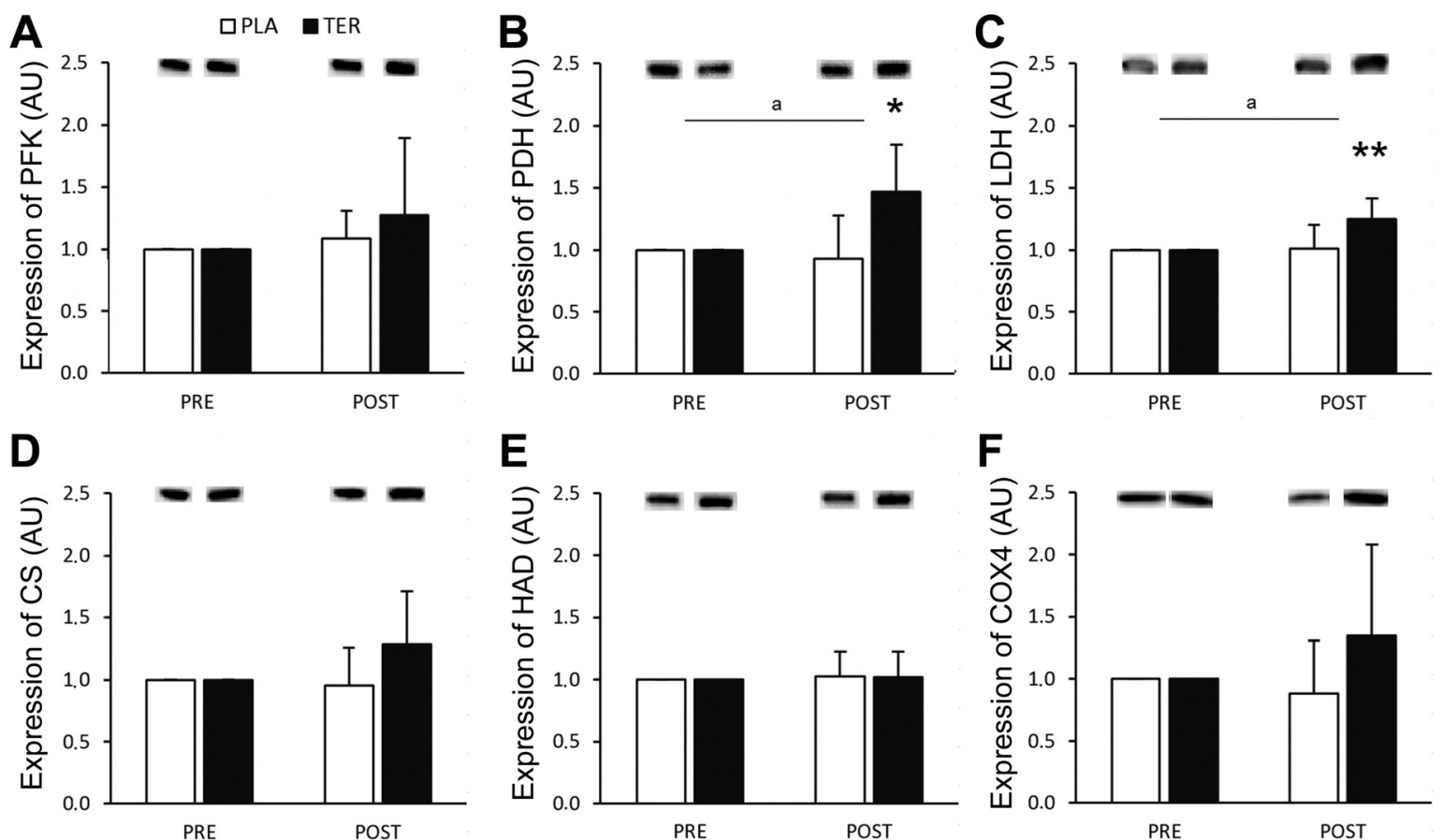

E

$\mathbf{F}$
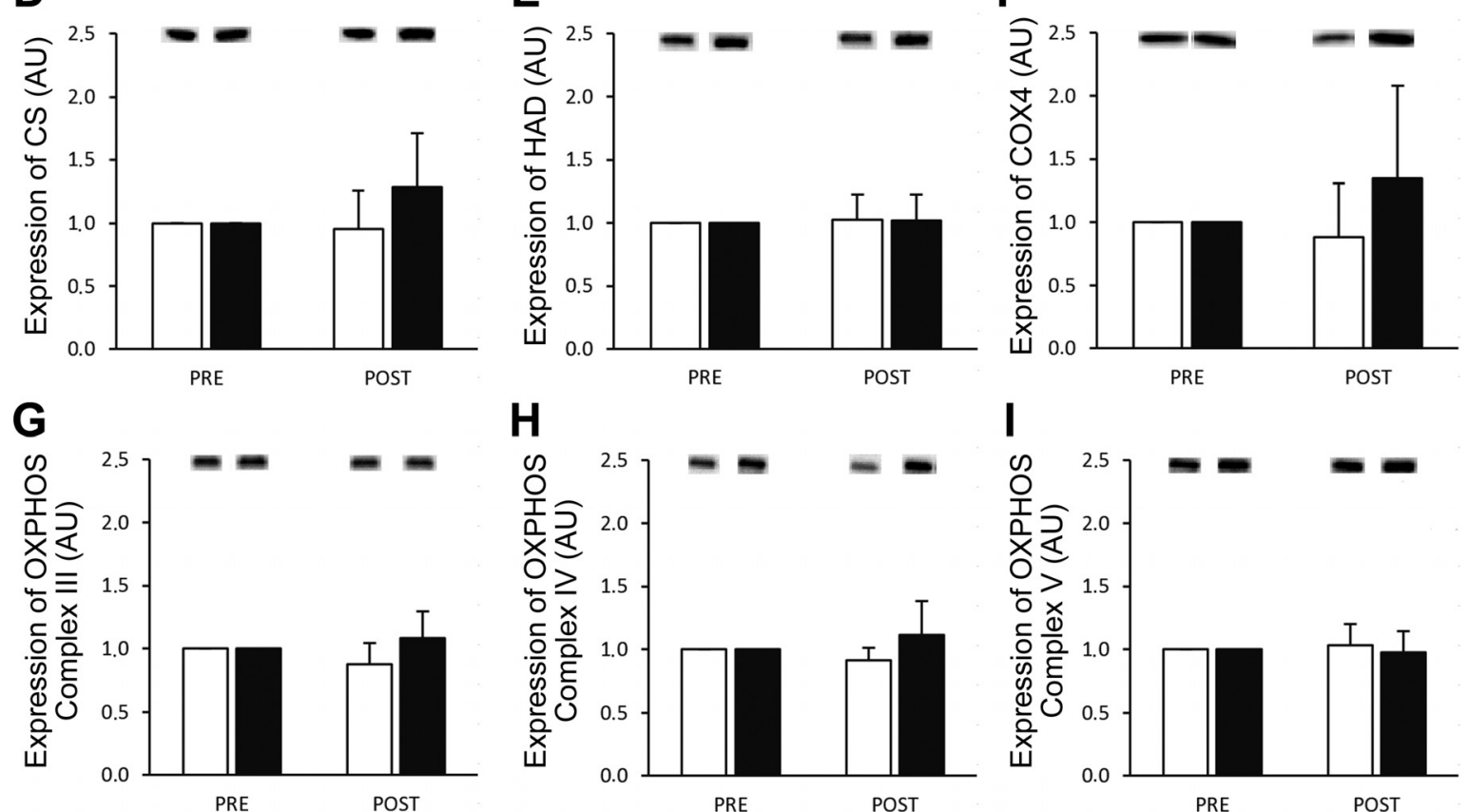

Fig. 4. Expression of glycolytic and oxidative enzymes before (PRE) and after (POST) 4 wk of oral administration of either TER (5 mg/30 kg bw twice daily; $n=9)$ or PLA $(n=9)$. A: phosphofructokinase (PFK). B: pyruvate dehydrogenase (PDH). C: lactate dehydrogenase. $D$ : citrate synthase (CS). E: hydroxyacyl CoA dehydrogenase (HAD). $F$ : cytochrome $c$ oxidase 4 (COX4). G: OXPHOS complex III. $H$ : OXPHOS complex IV. I: OXPHOS complex V. Representative blots from same membrane and subjects are presented. Data are presented as means \pm SD. Values are relative to PRE. ${ }^{a}$ Significant $(P \leq 0.05)$ interaction (treatment $\times$ time) between TER and PLA with the intervention. *Different $(P \leq 0.05)$ from PRE (within-group). **Different $(P \leq 0.01)$ from PRE (within-group).

higher when measured as CSA of muscle fibers compared with lean body mass $(17,38,42,79)$. In accordance, we observed that the increase in lean body mass induced by terbutaline treatment was $3 \%$ when measured by DXA-scan, whereas the increase observed in CSA of muscle fibers was 13-15\%. Discrepancies of the studies in humans could also be attributed to differences in dosing regimen or the $\beta_{2}$-agonist used, since animal studies have shown that the hypertrophic response is
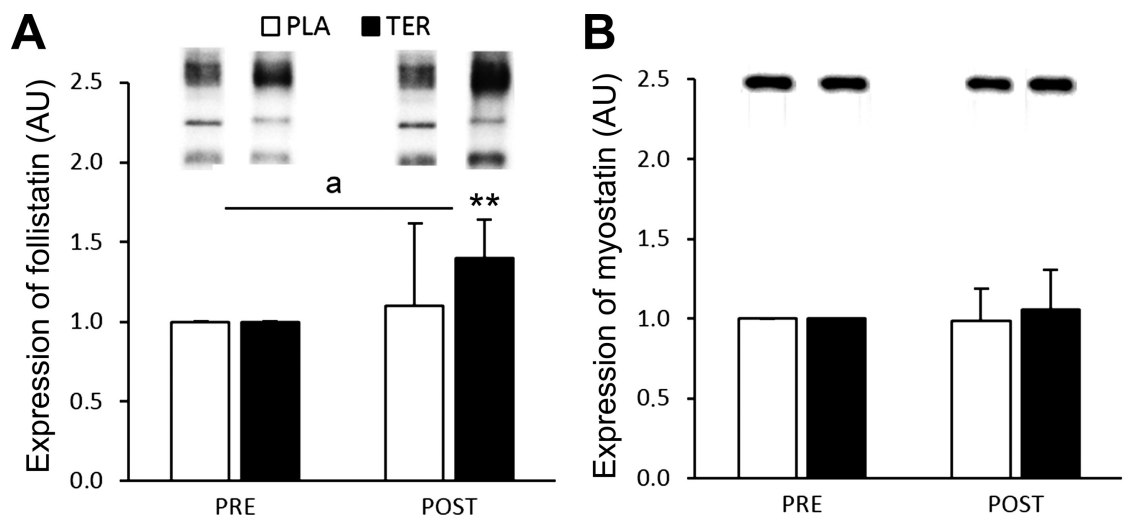

Fig. 5. Expression of follistatin and myostatin before (PRE) and after (POST) $4 \mathrm{wk}$ of oral administration of either TER $(5 \mathrm{mg} / 30 \mathrm{~kg}$ bw twice daily; $n=9)$ or PLA $(n=9)$. A: follistatin. $B$ : myostatin. Representative blots from same membrane and subjects are presented. Data are presented as means $\pm \mathrm{SD}$. Values are relative to PRE. ${ }^{\text {aSignificant }}(P \leq 0.01)$ interaction (treatment $\times$ time) between TER and PLA with the intervention. **Different $(P \leq 0.01)$ from PRE (within-group). 
related to dose, route of administration, duration, and type of $\beta_{2}$-agonist used $(14,50,64,67)$. This is also supported by acute administration studies of $\beta_{2}$-agonists in humans, in which supratherapeutic administration elicits a systemic response that enhances exercise performance and muscle force $(31,35,69)$, whereas therapeutic low-dose acute administration has no ergogenic effect on these parameters (59). Thus the choice of a supratherapeutic dose of terbutaline known to elicit a significant systemic response (32) may explain why a hypertrophic response was observed in the present study. Moreover, most of the human studies that have investigated chronic effects of $\beta_{2}$-agonists on lean body mass administered salbutamol $(10,12,39,40,45)$, whereas the present study, to our knowledge, is first to investigate the effect of terbutaline on hypertrophy in humans. Other factors that may explain discrepancies could also relate to differences in muscle fiber-type composition and training status of the included subjects, all of which have been speculated to affect the response to $\beta_{2^{-}}$ agonists in humans $(30,59,69)$. However, while slow- and fast-twitch fibers have been shown to respond differently to $\beta_{2}$-adrenergic stimulation in some animal studies $(21,43,66$, 81 ), we observed no differences in the hypertrophic response to terbutaline between MHC I and MHC II fibers of the vastus lateralis muscle. In addition, baseline characteristics in MHCdistribution of the vastus lateralis muscle, habitual training volume, and $\dot{\mathrm{V}}_{\mathrm{O}_{2 \max }}$ of the included subjects could not predict any change in CSA of MHC I and MHC II fibers and lean body mass with the intervention in a multiple linear regression of the present study. Thus our observations suggest that fiber-type composition and training status have limited influence on the hypertrophic response to chronic $\beta_{2}$-adrenergic stimulation in humans.

The gain in muscle mass elicited by terbutaline treatment in the present study was associated with a higher muscle expression of follistatin. This observation adds to that observed by Busquets et al. (8) where formoterol increased gene expression of follistatin, which was associated with skeletal muscle hypertrophy in tumor-bearing rats. In contrast to that observed in cell cultures and animals $(8,33,54)$, however, we observed no change in the expression of myostatin with terbutaline. This discrepancy may be explained by the duration of treatment. Indeed, Abo et al. (1) observed that expression of myostatin was higher after 21 days of clenbuterol treatment with no differences in the first week of treatment, suggesting that myostatin functions as a negative regulator in the latter stages of $\beta_{2}$-agonist treatment. Nonetheless, while the present observations suggest that follistatin may play a role in $\beta_{2}$-adrenergic mediated hypertrophy, the mechanisms are complex and possibly involve an interplay of several factors that directly or indirectly attenuate the negative regulatory action of the myostatin system on growth $(8,54,55,72,75)$.

Interestingly, we observed a reduction in fat mass with terbutaline, which is in agreement with observations in other species $(9,51)$. The fat-reducing effect of chronic $\beta_{2}$-adrenergic stimulation could be attributed to different factors. Foremost, studies in both humans and animals have shown that acute $\beta_{2}$-adrenergic stimulation increases thermogenesis (2) and administration of $\beta_{2}$-agonists elevates energy expenditure and oxidation of fat and carbohydrates in humans $(27,31,36$, 41). In accordance, animal studies have also shown that $\beta_{2^{-}}$ adrenoceptor knockout models develop obesity (4). Lastly, the increase in lean body mass associated with terbutaline treatment in the present study may have elevated the basal metabolic rate. Nonetheless, previous studies found no effect of chronic administration of oral salbutamol on fat mass in humans $(40,45)$, which may be related to differences in dosing regimen as discussed above.

In conclusion, the present study demonstrated that muscle hypertrophy is the primary mechanism by which chronic administration of $\beta_{2}$-agonists enhances muscle force and power output during maximal cycling in humans. Furthermore, the study showed that the hypertrophic response to chronic $\beta_{2^{-}}$ adrenergic stimulation with terbutaline is similar in slow- and fast-twitch muscle fibers of humans and that the hypertrophic response is associated with increased expression of muscle follistatin. Lastly, our study showed that chronic administration of terbutaline does not compromise $\dot{\mathrm{V}}_{2}$ max , incremental cycling performance, or muscle expression of oxidative enzymes. Given the increased muscle mass, muscle force, and power output during maximal cycling along with the higher expression of proteins involved in ion handling as well as in lactate production and clearance, our observations indicate that the response to $\beta_{2}$-adrenergic stimulation in skeletal muscle is comparable to that observed with resistance training and speed endurance training $(38,47,68)$.

Although produced for treatment of bronchoconstriction (74), $\beta_{2}$-agonists have been used to improve feed efficiency and meat quality in livestock (49) and bodybuilders have misused $\beta_{2}$-agonists as pharmacological supplement in their training $(20,56,60)$. Consequently, antidoping restrictions have been introduced towards $\beta_{2}$-agonists in competitive sports. The muscle accretion associated with $\beta_{2}$-agonists has also led to the suggestion that these drugs might be applicable in treatment of muscle-wasting disorders and in prevention of strength loss incurred from spaceflight $(10,11,12,34,44)$. Although the present study supports that $\beta_{2}$-agonists can be used to increase muscle mass and force, administration of high doses of $\beta_{2}$-agonists may be associated with side effects. In rats, high-dose treatment with clenbuterol has been shown to induce apoptosis in heart and soleus muscle (7). The deleterious effects of chronic treatment with $\beta_{2}$-agonists, however, are dose dependent and are as such only evident in very high doses that are not applied to humans (6). Therefore, it seems unlikely that therapeutic treatment would affect the heart deleteriously in humans. Given the performance-enhancing nature of acute $(19,30,35)$ and chronic $\beta_{2}$-adrenergic stimulation on muscle mass, muscle force (45), and power output $(30,39,69)$ during maximal exercise, it seems logical that systemic use of $\beta_{2^{-}}$ agonists should remain on the list of prohibited substances in competitive sports.

\section{ACKNOWLEDGMENTS}

Martin Thomassen, Pernille Emilie Petersen, and Nanna Krogh are acknowledged for their excellent technical assistance with the Western blotting and single fiber analysis.

\section{GRANTS}

The study was supported by grants from the World Anti-doping Agency, the Danish Ministry of Culture, and Anti-doping Denmark.

\section{DISCLOSURES}

No conflicts of interest, financial or otherwise, are declared by the author(s). 


\section{AUTHOR CONTRIBUTIONS}

Author contributions: M.H., A.K., N.O., V.B., and J.B. conception and design of research; M.H., A.K., J.O., S.J., C.H., S.H., N.O., V.B., and J.B. performed experiments; M.H., A.K., J.O., S.J., C.H., S.H., N.O., V.B., and J.B. analyzed data; M.H., A.K., J.O., S.J., C.H., S.H., N.O., V.B., and J.B. interpreted results of experiments; M.H., J.O., S.J., C.H., and S.H. prepared figures; M.H. drafted manuscript; M.H., A.K., J.O., S.J., C.H., S.H., N.O., V.B., and J.B. edited and revised manuscript; M.H., A.K., J.O., S.J., C.H., S.H., N.O., V.B., and J.B. approved final version of manuscript.

\section{REFERENCES}

1. Abo T, Iida RH, Kaneko S, Suga T, Yamada H, Hamada Y, Yamane A. IGF and myostatin pathways are respectively induced during the earlier and the later stages of skeletal muscle hypertrophy induced by clenbuterol, a beta(2)-adrenergic agonist. Cell Biochem Funct 30: 671-676, 2012.

2. Arch JR, Ainsworth AT, Cawthorne MA, Piercy V, Sennitt MV, Thody VE, Wilson C, Wilson S. Atypical beta-adrenoceptor on brown adipocytes as target for anti-obesity drugs. Nature 309: 163-165, 1984.

3. Bachasson D, Millet G, Decorte N, Wuyam B, Levy P, Verges S. Quadriceps function assessment using an incremental test and magnetic neurostimulation: a reliability study. J Electromyogr Kinesiol 23: 649658, 2013.

4. Bachman ES, Dhillon H, Zhang CY, Cinti S, Bianco AC, Kobilka BK, Lowell BB. betaAR signaling required for diet-induced thermogenesis and obesity resistance. Science 297: 843-845, 2002.

5. Bottinelli R, Canepari M, Pellegrino MA, Reggiani C. Force-velocity properties of human skeletal muscle fibres: myosin heavy chain isoform and temperature dependence. J Physiol 495: 573-586, 1996.

6. Burniston JG, Clark WA, Tan LB, Goldspink DF. Dose-dependent separation of the hypertrophic and myotoxic effects of the beta(2)adrenergic receptor agonist clenbuterol in rat striated muscles. Muscle Nerve 33: 655-663, 2006.

7. Burniston JG, Tan LB, Goldspink DF. beta2-Adrenergic receptor stimulation in vivo induces apoptosis in the rat heart and soleus muscle. $J$ Appl Physiol 98: 1379-1386, 2005.

8. Busquets S, Toledo M, Marmonti E, Orpi M, Capdevila E, Betancourt A, Lopez-Soriano FJ, Argiles JM. Formoterol treatment downregulates the myostatin system in skeletal muscle of cachectic tumour-bearing rats. Oncol Lett 3: 185-189, 2012.

9. Carter WJ, Lynch ME. Comparison of the effects of salbutamol and clenbuterol on skeletal muscle mass and carcass composition in senescent rats. Metabolism 43: 1119-1125, 1994.

10. Caruso JF, Hamill JL, Yamauchi M, Cook TD, Mercado DR, Wickel EE. Albuterol and exercise effects on ankle extensor strength during 40 days of unloading. Aviat Space Environ Med 79: 577-584, 2008.

11. Caruso JF, Hamill JL, De Garmo N. Oral albuterol doping during the latter stages of a resistance exercise program. J Strength Cond Res 19: 102-107, 2005.

12. Caruso JF, Signorile JF, Perry AC, Leblanc B, Williams R, Clark M, Bamman MM. The effects of albuterol and isokinetic exercise on the quadriceps muscle group. Med Sci Sports Exerc 27: 1471-1476, 1995.

13. Castle A, Yaspelkis BB, Kuo CH 3rd, Ivy JL. Attenuation of insulin resistance by chronic beta2-adrenergic agonist treatment possible muscle specific contributions. Life Sci 69: 599-611, 2001.

14. Choo JJ, Horan MA, Little RA, Rothwell NJ. Anabolic effects of clenbuterol on skeletal muscle are mediated by $\beta_{2}$-adrenoceptor activation. Am J Physiol Endocrinol Metab 263: E50-E56, 1992.

15. Clausen T. $\mathrm{Na}^{+}-\mathrm{K}^{+}$pump regulation and skeletal muscle contractility. Physiol Rev 83: 1269-1324, 2003.

16. Collomp K, Candau R, Lasne F, Labsy Z, Prefaut C, De Ceaurriz J. Effects of short-term oral salbutamol administration on exercise endurance and metabolism. J Appl Physiol 89: 430-436, 2000.

17. Cribb PJ, Williams AD, Stathis CG, Carey MF, Hayes A. Effects of whey isolate, creatine, and resistance training on muscle hypertrophy. Med Sci Sports Exerc 39: 298-307, 2007.

18. Crivelli G, Millet GP, Gremion G, Borrani F. Effects of salbutamol on the contractile properties of human skeletal muscle before and after fatigue. Acta Physiol (Oxf) 203: 311-320, 2011.

19. Decorte N, Bachasson D, Guinot M, Flore P, Levy P, Verges S, Wuyam B. Effect of salbutamol on neuromuscular function in endurance athletes. Med Sci Sports Exerc 45: 1925-1932, 2013.
20. Delbeke FT, Desmet N, Debackere M. The abuse of doping agents in competing body builders in Flanders (1988-1993). Int J Sports Med 16: 66-70, 1995.

21. Dodd SL, Powers SK, Vrabas IS, Criswell D, Stetson S, Hussain R. Effects of clenbuterol on contractile and biochemical properties of skeletal muscle. Med Sci Sports Exerc 28: 669-676, 1996.

22. Duncan ND, Williams DA, Lynch GS. Deleterious effects of chronic clenbuterol treatment on endurance and sprint exercise performance in rats. Clin Sci 98: 339-347, 2000.

23. Emery PW, Rothwell NJ, Stock MJ, Winter PD. Chronic effects of beta 2-adrenergic agonists on body composition and protein synthesis in the rat. Biosci Rep 4: 83-91, 1984.

24. Fitch KD. Therapeutic use exemptions (TUEs) at the Olympic Games 1992-2012. Br J Sports Med 47: 815-818, 2013.

25. Frontera WR, Larsson L. Contractile studies of single human skeletal muscle fibers: a comparison of different muscles, permeabilization procedures, and storage techniques. Muscle Nerve 20: 948-952, 1997.

26. Harcourt LJ, Schertzer JD, Ryall JG, Lynch GS. Low dose formoterol administration improves muscle function in dystrophic mdx mice without increasing fatigue. Neuromuscul Disord 17: 47-55, 2007.

27. Hoeks J, van Baak MA, Hesselink MK, Hul GB, Vidal H, Saris WH, Schrauwen P. Effect of $\beta_{1}$ - and $\beta_{2}$-adrenergic stimulation on energy expenditure, substrate oxidation, and UCP3 expression in humans. Am J Physiol Endocrinol Metab 285: E775-E782, 2003.

28. Hoshino D, Yoshida Y, Holloway GP, Lally J, Hatta H, Bonen A. Clenbuterol, a $\beta_{2}$-adrenergic agonist, reciprocally alters PGC- $1 \alpha$ and RIP140 and reduces fatty acid and pyruvate oxidation in rat skeletal muscle. Am J Physiol Regul Integr Comp Physiol 302: R373-R384, 2012.

29. Hopkins WG. A spreadsheet for analysis of straightforward controlled trials (online). Sportscience 7: sportsci.org/jour/03/wghtrials.htm, 2003.

30. Hostrup M, Kalsen A, Auchenberg M, Bangsbo J, Backer V. Effects of acute and 2-wk administration of oral salbutamol on exercise performance and muscle strength in athletes. Scand J Med Sci Sports 2014 Jul 31 [Epub ahead of print].

31. Hostrup M, Kalsen A, Bangsbo J, Hemmersbach P, Karlsson S, Backer V. High-dose inhaled terbutaline increases muscle strength and enhances maximal sprint performance in trained men. Eur J Appl Physiol 114: 2499-2508, 2014.

32. Hostrup M, Kalsen A, Ørtenblad N, Juel C, Morch K, Rzeppa S, Karlsson S, Backer V, Bangsbo J. Beta2-adrenergic stimulation enhances $\mathrm{Ca}^{2+}$ release and contractile properties of skeletal muscles, and counteracts exercise-induced reductions in $\mathrm{Na}^{+} / \mathrm{K}^{+}$-ATPase Vmax in trained men. J Physiol 592: 5445-5459, 2014.

33. Ijiri D, Ishitani K, Shimamoto S, Ishimaru Y, Ohtsuka A. The effects of intraperitoneal clenbuterol injection on protein degradation and myostatin expression differ between the sartorius and pectoral muscles of neonatal chicks. Gen Comp Endocrinol 206: 111-117, 2014.

34. Joassard OR, Durieux AC, Freyssenet DG. beta2-Adrenergic agonists and the treatment of skeletal muscle wasting disorders. Int J Biochem Cell Biol 45: 2309-2321, 2013.

35. Kalsen A, Hostrup M, Bangsbo J, Backer V. Combined inhalation of $\beta 2$-agonists improves swim ergometer sprint performance but not highintensity swim performance. Scand J Med Sci Sports 24: 814-822, 2014.

36. Kalsen A, Hostrup M, Karlsson S, Hemmersbach P, Bangsbo J, Backer V. Effect of inhaled terbutaline on substrate utilization and 300-kcal time trial performance. J Appl Physiol 117: 1180-1187, 2014.

37. Koopman R, Gehrig SM, Leger B, Trieu J, Walrand S, Murphy KT, Lynch GS. Cellular mechanisms underlying temporal changes in skeletal muscle protein synthesis and breakdown during chronic $\beta$-adrenoceptor stimulation in mice. J Physiol 588: 4811-4823, 2010.

38. Kraemer WJ, Patton JF, Gordon SE, Harman EA, Deschenes MR, Reynolds K, Newton RU, Triplett NT, Dziados JE. Compatibility of high-intensity strength and endurance training on hormonal and skeletal muscle adaptations. J Appl Physiol 78, 976-989, 1995.

39. Le Panse B, Arlettaz A, Portier H, Lecoq AM, De Ceaurriz J, Collomp K. Short term salbutamol ingestion and supramaximal exercise in healthy women. Br J Sports Med 40: 627-631, 2006.

40. Le Panse B, Collomp K, Portier H, Lecoq AM, Jaffre C, Beaupied H, Richard O, Benhamou L, De Ceaurriz J, Courteix D. Effects of short-term salbutamol ingestion during a Wingate test. Int J Sports Med 26: 518-523, 2005.

41. Lee P, Day RO, Greenfield JR, Ho KK. Formoterol, a highly beta2selective agonist, increases energy expenditure and fat utilisation in men. Int J Obes 37: 593-597, 2013. 
42. Leenders M, Verdijk LB, Van der Hoeven L, Van Kranenburg J, Nilwik R, Wodzig WK, Senden JM, Keizer HA, Van Loon LJ. Protein supplementation during resistance-type exercise training in the elderly. Med Sci Sports Exerc 45: 542-552, 2013.

43. Lynch GS, Hayes A, Campbell SP, Williams DA. Effects of beta 2-agonist administration and exercise on contractile activation of skeletal muscle fibers. J Appl Physiol 81: 1610-1618, 1996.

44. Lynch GS, Ryall JG. Role of beta-adrenoceptor signaling in skeletal muscle: implications for muscle wasting and disease. Physiol Rev 88: 729-767, 2008.

45. Martineau L, Horan MA, Rothwell NJ, Little RA. Salbutamol, a beta 2 -adrenoceptor agonist, increases skeletal muscle strength in young men. Clin Sci 83: 615-621, 1992.

46. Masoli M, Fabian D, Holt S, Beasley R; Global Initiative for Asthma (GINA) Program. The global burden of asthma: executive summary of the GINA Dissemination Committee report. Allergy 59: 469-478, 2004.

47. McKenna MJ, Bangsbo J, Renaud JM. Muscle $\mathrm{K}^{+}, \mathrm{Na}^{+}$, and $\mathrm{Cl}$ disturbances and $\mathrm{Na}^{+}-\mathrm{K}^{+}$pump inactivation: implications for fatigue. $J$ Appl Physiol 104: 288-295, 2008.

48. Merton PA. Voluntary strength and fatigue. J Physiol 123: 553-564, 1954.

49. Mitchell GA, Dunnavan G. Illegal use of beta-adrenergic agonists in the United States. J Anim Sci 76: 208-211, 1998.

50. Moore NG, Pegg GG, Sillence MN. Anabolic effects of the $\beta_{2}$-adrenoceptor agonist salmeterol are dependent on route of administration. Am J Physiol Endocrinol Metab 267: E475-E484, 1994.

51. Mounier R, Cavalie H, Lac G, Clottes E. Molecular impact of clenbuterol and isometric strength training on rat EDL muscles. Pfü̈gers Arch 453: 497-507, 2007

52. Ohnuki Y, Umeki D, Mototani Y, Jin H, Cai W, Shiozawa K, Suita K, Saeki Y, Fujita T, Ishikawa Y, Okumura S. Role of cyclic AMP sensor Epac1 in masseter muscle hypertrophy and myosin heavy chain transition induced by beta2-adrenoceptor stimulation. J Physiol 592: 5461-5475, 2014.

53. Ørtenblad N, Nielsen J, Saltin B, Holmberg HC. Role of glycogen availability in sarcoplasmic reticulum $\mathrm{Ca}^{2+}$ kinetics in human skeletal muscle. J Physiol 589: 711-725, 2011.

54. Pearen MA, Ryall JG, Lynch GS, Muscat GE. Expression profiling of skeletal muscle following acute and chronic beta2-adrenergic stimulation: implications for hypertrophy, metabolism and circadian rhythm. BMC Genomics 10: 448, 2009.

55. Pearen MA, Ryall JG, Maxwell MA, Ohkura N, Lynch GS, Muscat GE. The orphan nuclear receptor, NOR-1, is a target of beta-adrenergic signaling in skeletal muscle. Endocrinology 147: 5217-5227, 2006.

56. Perry H. Clenbuterol: a medal in tablet form? Br J Sports Med 27: 141, 1993.

57. Place N, Maffiuletti NA, Martin A, Lepers R. Assessment of the reliability of central and peripheral fatigue after sustained maximal voluntary contraction of the quadriceps muscle. Muscle Nerve 35: 486-495, 2007

58. Place N, Casartelli N, Glatthorn J, Maffiuletti N. Comparison of quadriceps inactivation between nerve and muscle stimulation. Muscle Nerve 42: 894-900, 2010.

59. Pluim BM, de Hon O, Staal JB, Limpens J, Kuipers H, Overbeek SE, Zwinderman AH, Scholten RJ. $\beta_{2}$-Agonists and physical performance: a systematic review and meta-analysis of randomized controlled trials. Sports Med 41: 39-57, 2011.

60. Prather ID, Brown DE, North P, Wilson JR. Clenbuterol: a substitute for anabolic steroids? Med Sci Sports Exerc 27: 1118-1121, 1995.

61. Price AH, Clissold SP. Salbutamol in the 1980s. A reappraisal of its clinical efficacy. Drugs 38: 77-122, 1989.

62. Price OJ, Hull JH, Backer V, Hostrup M, Ansley L. The impact of exercise-induced bronchoconstriction on athletic performance: a systematic review. Sports Med 44: 1749-1761, 2014

63. Py G, Ramonatxo C, Sirvent P, Sanchez AM, Philippe AG, Douillard A, Galbes O, Lionne C, Bonnieu A, Chopard A, Cazorla O, Lacampagne Candau RB. Chronic clenbuterol treatment compromises force production without directly altering skeletal muscle contractile machinery. J Physiol 593: 2071-2084, 2015.

64. Reeds PJ, Hay SM, Dorward PM, Palmer RM. The effect of betaagonists and antagonists on muscle growth and body composition of young rats (Rattus sp.). Comp Biochem Physiol C 89: 337-341, 1988.

65. Ricart-Firinga C, Stevens L, Canu MH, Nemirovskaya TL, Mounier Y. Effects of $\beta_{2}$-agonist clenbuterol on biochemical and contractile properties of unloaded soleus fibers of rat. Am J Physiol Cell Physiol 278: C582-C588, 2000.

66. Ryall JG, Gregorevic P, Plant DR, Sillence MN, Lynch GS. $\beta_{2}$-Agonist fenoterol has greater effects on contractile function of rat skeletal muscles than clenbuterol. Am J Physiol Regul Integr Comp Physiol 283: R1386R1394, 2002

67. Ryall JG, Sillence MN, Lynch GS. Systemic administration of beta2adrenoceptor agonists, formoterol and salmeterol, elicit skeletal muscle hypertrophy in rats at micromolar doses. Br J Pharmacol 147: 587-595, 2006.

68. Rønnestad BR, Hansen EA, Raastad T. Effect of heavy strength training on thigh muscle cross-sectional area, performance determinants, and performance in well-trained cyclists. Eur J Appl Physiol 108, 965-975, 2010.

69. Sanchez AM, Collomp K, Carra J, Borrani F, Coste O, Prefaut C, Candau R. Effect of acute and short-term oral salbutamol treatments on maximal power output in non-asthmatic athletes. Eur J Appl Physiol 112: 3251-3258, 2012.

70. Sanchez AM, Borrani F, Le Fur MA, Le Mieux A, Lecoultre V, Py G, Gernigon C, Collomp K, Candau R. Acute supra-therapeutic oral terbutaline administration has no ergogenic effect in non-asthmatic athletes. Eur J Appl Physiol 113: 411-418, 2013.

71. Seebacher F, Pollard SR, James RS. How well do muscle biomechanics predict whole-animal locomotor performance? The role of $\mathrm{Ca}^{2+}$ handling. J Exp Biol 215: 1847-1853, 2012.

72. Shi H, Zeng C, Ricome A, Hannon KM, Grant AL, Gerrard DE. Extracellular signal-regulated kinase pathway is differentially involved in $\beta$-agonist-induced hypertrophy in slow and fast muscles. Am J Physiol Cell Physiol 292: C1681-C1689, 2007.

73. Sirvent P, Douillard A, Galbes O, Ramonatxo C, Py G, Candau R, Lacampagne A. Effects of chronic administration of clenbuterol on contractile properties and calcium homeostasis in rat extensor digitorum longus muscle. PLoS One 9: e100281, 2014.

74. Solis-Cohen S. The use of adrenal substance in the treatment of asthma JAMA 34: 1164-1166, 1900.

75. Spurlock DM, McDaneld TG, McIntyre LM. Changes in skeletal muscle gene expression following clenbuterol administration. $B M C$ Genomics 7: 320, 2006.

76. Stevens L, Firinga C, Gohlsch B, Bastide B, Mounier Y, Pette D. Effects of unweighting and clenbuterol on myosin light and heavy chains in fast and slow muscles of rat. Am J Physiol Cell Physiol 279: C1558C1563, 2000

77. Strojnik V, Komi PV. Neuromuscular fatigue after maximal stretchshortening cycle exercise. J Appl Physiol 84: 344-350, 1998.

78. Suzuki J, Gao M, Xie Z, Koyama T. Effects of the beta 2-adrenergic agonist clenbuterol on capillary geometry in cardiac and skeletal muscles in young and middle-aged rats. Acta Physiol Scand 161: 317-326, 1997.

79. Terzis G, Georgiadis G, Stratakos G, Vogiatzis I, Kavouras S, Manta $\mathbf{P}$, Mascher H, Blomstrand E. Resistance exercise-induced increase in muscle mass correlates with p70S6 kinase phosphorylation in human subjects. Eur J Appl Physiol 102:, 145-152, 2008.

80. Verges S, Maffiuletti NA, Kerherve H, Decorte N, Wuyam B, Millet GY. Comparison of electrical and magnetic stimulations to assess quadriceps muscle function. J Appl Physiol 106: 701-710, 2009.

81. Zeman RJ, Ludemann R, Easton TG, Etlinger JD. Slow to fast alterations in skeletal muscle fibers caused by clenbuterol, a $\beta_{2}$-receptor agonist. Am J Physiol Endocrinol Metab 254: E726-E732, 1988.

82. Zhang KM, Hu P, Wang SW, Feher JJ, Wright LD, Wechsler AS, Spratt JA, Briggs FN. Salbutamol changes the molecular and mechanical properties of canine skeletal muscle. J Physiol 496: 211-220, 1996. 